Orbis Tertius, vol. XXII, $n^{\circ}$ 25, e042, junio 2017. ISSN 1851-7811

Universidad Nacional de La Plata

Facultad de Humanidades y Ciencias de la Educación

Centro de Estudios de Teoría y Crítica Literaria

\title{
Gisèle Sapiro, La sociología de la literatura.
}

\author{
Buenos Aires, Fondo de Cultura Económica, 2016, Colección Lengua y \\ Estudios Literarios, 168 páginas.
}

\section{Malena Botto}

El libro de Gisèle Sapiro — cuya publicación original en francés data de 2014- parte de una hipótesis susceptible de poner en discusión: la sociología de la literatura adolece de una "falta de institucionalización” que "contrasta con la riqueza de los trabajos producidos en su ámbito desde hace medio siglo" (p. 15). Quien lee no sólo infiere que este volumen se propone subsanar, a la manera de un "programa", la carencia señalada, sino que también se pregunta cuáles serían aquellos ámbitos en los que debería "institucionalizarse”: ¿como espacio curricular/disciplinar en la formación universitaria?, ¿a través de publicaciones especializadas?, etc. Para la autora, "la sociología de la literatura ha tenido que vencer la resistencia a la objetivación basada en la creencia en la naturaleza indeterminada y singular de las obras literarias. Demasiado 'sociológica' para los literatos y demasiado 'literaria' para los sociólogos...” (p. 15). Para la reseñista, la primera impresión es la de un cierto anacronismo: ¿cuáles son los estudios de referencia que aquí se llaman "literarios”, o desarrollados por los "literatos”? ¿los análisis filológicos, los de corte estructuralista, el biografismo? Parece en efecto que Sapiro — graduada en Literatura Comparada y Filosofía en Tel Aviv, luego discípula de Pierre Bourdieu y Doctora en Sociología por la École des Hautes Études en Sciences Sociales - considera como propios de los estudios literarios enfoques cualitativos "tradicionalmente usados" en la disciplina, como "análisis de documentos, estudio del contenido de las obras y/o de las críticas” (p. 16). Desde esta perspectiva, todo el estudio se propone superar lo que entiende como una dicotomía entre el “análisis interno” y el "análisis externo” de los fenómenos literarios.

Por otra parte, la autora se muestra altamente informada acerca de diversos desarrollos, muchos de ellos más transitados por los estudios literarios que por la sociología: la historia literaria, las teorías marxistas, la teoría de los campos de Bourdieu, los estudios poscoloniales, la sociología de las profesiones, la historia de la lectura, del libro y de la edición, la sociología del público. Son todas estas líneas las que pretende inscribir en

Cita sugerida: Botto, M. (2017). [Revisión del libro La sociología de la literatura por Gisèle Sapiro]. Orbis Tertius, 22(25), e042. https://doi.org/10.24215/18517811e042 
este "nuevo" campo de estudios, que así pasaría a absorber toda indagación que se ocupe de las mediaciones o que se pregunte por la literatura en tanto que hecho social.

Por lo demás, el libro es, en el mejor sentido del término, un manual: estudiantes y docentes pueden servirse de él para conocer o dar a conocer la existencia de variados enfoques y estudios que se inscriben en aquellas perspectivas llamadas "relacionales", que rechazan el principio de inmanencia. Sapiro realiza una reseña minuciosa, con notable claridad en la exposición y a partir de un corpus bibliográfico exhaustivo y actualizado. Articula esa exposición focalizando el problema, en cada uno de los cuatro capítulos, desde diferentes ángulos: desde el punto de vista de las perspectivas teóricas (Capítulo I), del ámbito de la producción (Capítulo II), de las obras literarias (Capítulo III) y del ámbito de la recepción (Capítulo IV).

El primer capítulo, “Teorías y enfoques sociológicos de la literatura”, supone un recorrido histórico. La autora parte de aquellos estudios que denomina "protosociológicos", inaugurados por De la literatura considerada en sus relaciones con las instituciones sociales de Madame de Staëlal al despuntar el siglo XIX, y que se extienden para Sapiro hasta mediados del XX. Destaca los trabajos de corte positivista de Hippolyte Taine y la constitución de la historia literaria de Gustave Lanson. Luego, corresponde la mención de Levin Schüking -el "precursor" de Bourdieu - con su teorización sobre el gusto y, como aporte generalmente soslayado, se rescata el trabajo de Lucien Febvre sobre Rabelais (1942), que conecta la historia literaria con la historia de las mentalidades.

Más allá de estos antecedentes, la sociología de la literatura encuentra su origen al amparo de las teorías marxistas, que consiguen "desplazar el análisis del nivel individual al nivel colectivo" (p. 32). Sapiro distingue en los estudios literarios marxistas dos grandes orientaciones: la primera, deudora de la obra de Georg Lukács, indaga en el análisis entre las formas literarias y las situaciones sociales que propician su emergencia, centrándose fundamentalmente en las obras; la otra, que profundiza el camino trazado por Antonio Gramsci y formalizado por Arnold Hauser, focaliza sobre todo las condiciones de producción y de recepción, abriendo el camino para los estudios culturales. La teoría de la literatura como acto de comunicación de Robert Escarpit, el estructuralismo genético de Lucien Goldmann, los postulados de la Escuela de Frankfurt, las intervenciones de Pierre Macherey en torno a la noción de producción, las críticas althusserianas a la noción de causalidad, con las objeciones propuestas por Frederic Jameson a esas mismas críticas, constituyen algunas de las perspectivas reseñadas en esta presentación.

Un apartado diferente dentro del mismo capítulo está dedicado a los enfoques estructural-funcionalistas, donde se incluye la mención de Pierre Bourdieu y su teoría de los campos — sin una particular referencia a las revisiones y desplazamientos operados en los desarrollos de Bourdieu entre los primeros postulados en la década de los '60 y posteriores reformulaciones a propósito de algunos conceptos claves de su teoría. Sapiro recurrirá a diversos lineamientos y categorías teóricas (por ejemplo, la noción de "literatura menor" de Deleuze y Guattari) para recolocar la teoría de los campos en un escenario internacional, en el que la relativa o en ciertos casos "débil” autonomía de los campos nacionales será vista en vinculación con una situación geopolítica que obliga a reconsiderar las relaciones entre culturas dominantes o dominadas.

El capítulo II se ocupa de “las condiciones sociales de producción de las obras”. Siguiendo a Bourdieu, Sapiro menciona como determinantes para la constitución de la autonomía relativa las relaciones con los poderes políticos, religiosos o económicos. Además, otorga un lugar central a la configuración del rol social del escritor, aspecto que funciona como aglutinante para explicar las relaciones entre las obras literarias y los condicionantes "externos".

La autora sostiene la necesidad de estudiar las tomas de posición e inscripción social de los escritores en su especificidad, distinguiéndolas de la historia política de los intelectuales, con la que obviamente se emparentan. Junto a la emergencia del mercado, la división del trabajo intelectual que se consolida en el 
siglo XIX supone para la literatura la pérdida de "ciertas áreas de actividad” que son cooptadas por nuevas profesiones, tal como antes había sucedido con el campo religioso. Tal transformación constituye una de las razones de "la politización de la literatura y la reacción conservadora que engendró en su seno” (p. 55). Otra inclusión interesante tiene lugar cuando la autora recurre a la sociología de las profesiones para señalar la "débil profesionalización" del campo literario, en contraste con la "multiplicidad de instancias de difusión (...) y consagración” (p. 59). Completa estos apartados una breve consideración con sentido histórico de las diferencias de clase, género, grados de escolarización de los escritores y consolidación de instituciones propias de la vida literaria.

El tercer capítulo, "La sociología de las obras”, postula la necesidad de superar tanto la "teoría del reflejo" como la "ilusión biográfica” y el supuesto romántico del "creador increado". Sapiro propondrá una doble vía para trascender esa dicotomía: considerar, por una parte, el espacio conformado por las representaciones y discursos sociales de un contexto dado; por otro lado, atender al "espacio de posibles" estructurado a partir del campo mismo: géneros, modelos y modos de la praxis. La noción de "trayectorias” y la de "estrategias" —empleada en sentido bourdiano — son las herramientas metodológicas que sirven para superar los postulados del biografismo.

Por otra parte, en buena medida los "espacios de posibles" dan cuenta de distintas funciones sociales que pueda adquirir la literatura. El capítulo expande y comenta las relaciones que establece Bourdieu entre la estructuración del campo y el proyecto creador. Solo que, en este caso, la investigadora coloca de entrada el producto resultante (la obra) en un espacio discursivo de mayor amplitud, inscribiéndose en la operación de “destabicamiento" que propone Marc Angenot en su teorización sobre el discurso social. Esa opción se vuelve manifiesta cuando se recuperan las discusiones en torno del canon y la concepción de la literatura en relación con la identidad nacional, fruto de la historia literaria. En la discusión de estos procesos destacan las referencias a los desarrollos de Pascale Casanova y la "república mundial". Se vuelve preciso “desnacionalizar la historia literaria” "historizando las categorías de entendimiento erudito" (p. 97), operación que permite integrar en el análisis fenómenos de transferencias e intercambios históricamente producidos entre culturas o entre sectores — dominantes o subordinados — de distintas culturas. "La constatación de la hibridez inicial de las literaturas nacionales lleva a relativizar la idea de que el fenómeno de 'mestizaje' (...) sería propio de la globalización”, puntualiza Sapiro (p. 96).

En el análisis de las mediaciones cabe señalar el lugar relevante otorgado al sistema educativo, centralidad que se sostiene en la advertencia de que el campo literario es un espacio social que no proporciona ámbitos de formación específica. Esta mediación escolar, poco atendida e incluso desprestigiada por Bourdieu en su estudio sobre el campo aparece, en palabras de Sapiro, “ocultada con demasiada frecuencia” (p. 90).

En lo que refiere a la recepción (capítulo IV), se procura un análisis que equilibre los que aparecen como "puntos de anclaje" interpretativos, ofrecidos por los textos, y lo que Sapiro denomina "iniciativas anexionistas", incentivadas por la circulación de las obras en contextos muchas veces alejados del contexto de producción. Dos cuestiones destacan aquí, en contraste con la teoría bourdiana. La primera, la consideración de los entornos textuales y los soportes, los paratextos y las modalidades de diseño iconográfico que suponen una forma de política editorial susceptible de orientar una recepción jerarquizada, previa a la interpretación misma. Luego, una reflexión sobre la circulación trasnacional de las obras, que diseña un nuevo ámbito en el que se revelan las tensiones que atraviesan a las literaturas poscoloniales, toda vez que, desde los centros culturales, se postulan cánones "representativos” de la periferia —expresados en colecciones editoriales y distinciones - que pueden dar lugar un "exotismo" totalmente contrario a la toma de posición que dio origen a esas obras. 
El lugar reservado para las mediaciones ejercidas por los agentes propios del campo (en particular, la crítica literaria), es el de generadores de "anexiones" que estabilizan nuevos sentidos para los textos. La caracterización que Sapiro realiza de este subcampo adolece de cierta rigidez, contrasta con la caracterización del "discurso social” ya mencionada y en definitiva replica —a partir de la postulación de un polo dominante y otro dominado, y de un mayor o menor grado de autonomía o heteronomía — el modelo que Bourdieu estableciera hace medio siglo para describir las tomas de posición de los escritores.

El trabajo de Sapiro actualiza las investigaciones sobre la relación entre literatura y sociedad, renovando la tradición que en nuestro país se halla representada, sobre todo, por los análisis y las “importaciones” teóricas realizadas por Carlos Altamirano y Beatriz Sarlo. En contraste con esos antecedentes, cabe señalar que la concepción de "teoría" que emerge de las consideraciones de Sapiro la acerca mucho más a su formulación en el campo sociológico — claramente articulada con un método, inscripto en un paradigma cualitativo o cuantitativo que pueda conjugarse a partir de la triangulación en los estudios de caso específicos- que a lo que conocemos como teorías literarias. El hecho de depositar las estrategias de validación en la articulación entre teoría y método así concebidos conlleva resultados dispares: por un lado, una serie de sugerencias metodológicas que toman la forma de prescripciones pero que no siempre se sustentan en los estudios de caso que la autora se preocupa en referir, precisamente para sostener esa articulación. Por otra parte, y a pesar de las excesivas referencias al ámbito francés, se dijo ya que la consideración de nuevas formas de producción y circulación constituye una puesta al día que otorga valor a este estudio, junto con la presentación de un panorama exhaustivo de teorías y enfoques, que lo proyectan como obra de consulta y referencia. 